Review

\title{
Cerebral Venous Sinus Thrombosis following COVID-19 Vaccination: Analysis of 552 Worldwide Cases
}

\author{
Cesare de Gregorio $^{1, *(\mathbb{D}}$, Luigi Colarusso ${ }^{1} \mathbb{D}$, Giuseppe Calcaterra ${ }^{2}$, Pier Paolo Bassareo ${ }^{3} \mathbb{D}$, Antonio Ieni $^{4}$, \\ Anna Teresa Mazzeo ${ }^{5}$, Giuseppe Ferrazzo ${ }^{1}$, Alberto Noto ${ }^{5}$, Ioanna Koniari ${ }^{6}$, Jawahar L. Mehta ${ }^{7}$ (D)
} and Nicholas G. Kounis 8 (D)

check for updates

Citation: de Gregorio, C.; Colarusso, L.; Calcaterra, G.; Bassareo, P.P.; Ieni, A.; Mazzeo, A.T.; Ferrazzo, G.; Noto, A.; Koniari, I.; Mehta, J.L.; et al. Cerebral Venous Sinus Thrombosis following COVID-19 Vaccination: Analysis of 552 Worldwide Cases. Vaccines 2022, 10, 232. https:// doi.org/10.3390/vaccines10020232

Academic Editor: François Meurens

Received: 13 January 2022

Accepted: 30 January 2022

Published: 3 February 2022

Publisher's Note: MDPI stays neutral with regard to jurisdictional claims in published maps and institutional affiliations.

Copyright: (C) 2022 by the authors. Licensee MDPI, Basel, Switzerland. This article is an open access article distributed under the terms and conditions of the Creative Commons Attribution (CC BY) license (https:// creativecommons.org/licenses/by/ $4.0 /)$.
1 Department of Clinical and Experimental Medicine, Division of Cardiology, G. Martino University Hospital Medical School of Messina, 98125 Messina, Italy; luigi.colarusso@alice.it (L.C.); fergiu89@libero.it (G.F.)

2 Department of Cardiology, Postgraduate Medical School of Cardiology, University of Palermo, 90127 Palermo, Italy; peppinocal7@gmail.com

3 Department of Cardiology, Mater Misericordiae University Hospital Crumlin, University College of Dublin, D07R2WY Dublin, Ireland; piercard@inwind.it

4 Pathology Unit, Department of Human Pathology G. Barresi, G. Martino University Hospital Medical School of Messina, 98125 Messina, Italy; antonio.ieni@unime.it

5 Department of Human Pathology G. Barresi, Division of Anesthesia and Critical Care, G. Martino University Hospital Medical School of Messina, 98125 Messina, Italy; annateresamazzeo@unime.it (A.T.M.);

alberto.noto@unime.it (A.N.)

6 Department of Cardiology, University Hospital of South Manchester, NHS Foundation Trust, Manchester M23 9LT, UK; iokoniari@yahoo.gr

7 Department of Medicine, University of Arkansas for Medical Sciences and the Veterans Affairs Medical Center, Little Rock, AR 72205, USA; mehtajl@uams.edu

8 Department of Internal Medicine, Division of Cardiology, University of Patras Medical School, 26221 Patras, Greece ngkounis@otenet.gr

* Correspondence: cesare.degregorio@unime.it; Tel.: +39-090-221-3533-98123

Abstract: To date, billions of vaccine doses have been administered to restrain the current COVID-19 pandemic worldwide. Rare side effects, including intravascular blood clots, were reported in the general population after vaccination. Among these, cerebral venous sinus thrombosis (CVST) has been considered the most serious one. To shed further light on such an event, we conducted a literature search for case descriptions of CVST in vaccinated people. Findings were analyzed with emphasis on demographic characteristics, type of vaccine, site of thrombosis, clinical and histopathological findings. From 258 potential articles published till September 2021, 41 studies were retrieved for a total of 552 patients. Of these, 492 patients (89.1\%) had received AZD1222/Vaxzevria, 45 (8.2\%) BNT162b2/CX-024414 Spikevax, 15 (2.7\%) JNJ-78436735, and 2 (0.3\%) Covishield vaccine. CVST occurred in 382 women and 170 men (mean aged 44 years), and the median timing from the shot was 9 days (range 2-45). Thrombi were predominantly seen in transverse (84\%), sigmoid (66\%), and/or superior sagittal (56\%) sinuses. Brain injury (chiefly intracranial bleeding) occurred in $32 \%$ of cases. Of 426 patients with detailed clinical course, $63 \%$ were discharged in good clinical conditions, at times with variable neurological sequelae, whereas $37 \%$ deceased, largely due to brain injury. This narrative review confirmed CVST as a rare event after (adenoviral vector) COVID-19 vaccination, with a women/men rate ratio of 2.25. Though the pathogenesis of thrombosis is still under discussion, currently available histopathological findings likely indicate an underlying immune vasculitis.

Keywords: cardiovascular disease; cerebral venous sinus thrombosis; COVID-19 pandemic; side effects; vaccination

\section{Introduction}

A collective immunization is an important step forward in weathering the COVID-19 pandemic. However, side effects have been reported after vaccine shots. Rare serious 
adverse events such as vascular syndromes, myocarditis, pericarditis, neurological disease, and other illnesses have been described in a variable proportion of recipients [1-5]. Vascular thrombosis occurred in some individuals, particularly young women, at times surprisingly involving the cerebral venous sinus (CVS) vessels. Blood clots were often associated with thrombocytopenia, and a novel vaccine-induced immune thrombotic thrombocytopenia (VITT) syndrome was established as of February $2021[5,6]$. Since then, a rising body of literature on such cases and possible pathophysiological mechanisms have been published. The VITT syndrome closely resembles the heparin-induced thrombocytopenia (HIT) identified first by Kelton in 1986 [7] and more recently reprised by Greinacher [8], with the difference that VITT is not triggered by heparin administration.

In addition, in the general population, CVS thrombosis (CVST) has been considered a very rare disease, affecting as many as one in 1,000,000 people and one in 5000 to 15,000 hospitalized patients for various diseases $[9,10]$.

As early cases of CVST after vaccination appeared in the literature [11], a warning on neurological disorders occurring within 15 days after the first shot was provided by health authorities all over the world. In March 2021, the European Medicines Agency reported a few cases of CVST thrombosis related to vaccines [12], but many more were described afterwards.

In order to shed further light on the main clinical, pathophysiological, and prognostic features of this new syndrome, we conducted a literature search of published reports describing CVST after COVID-19 vaccination.

\section{Materials and Methods}

A literature search through PubMed, Medline, Life science journals, and SCOPUS database was performed for case series and single reports of CVST following COVID19 vaccination, published between December 2020 and September 2021. The following MESH terms were used for searching: "acute cardiovascular events", "cardiovascular disease", "COVID-19", "cerebral vein/venous thrombosis", "deep venous thrombosis", "SARS-CoV-2", "side-effects", "thrombosis", "vaccine", together with "ChAdOx", "AstraZeneca", "Vaxzevria”, “Ad26.COV2.S", "Janssen", “Johnson", “mRNA-1273”, “Moderna", "BNT162b2", "Pfizer", "Comirnaty", were applied. We first evaluated the titles and abstracts of each article to be suitable for inclusion in this review. Studies must have been written in English, reporting CVST as by cranial computed tomography or magnetic resonance imaging after vaccine shots, in the context of a VITT syndrome. Clinical features, type of vaccine, demographic characteristics, imaging, sites of CVST, prevalence of thrombocytopenia and PF4-polyanion antibodies, therapeutic approaches, and histopathological findings, were anonymously recognized and analyzed.

\section{Results}

\subsection{Patient Population}

From a total of 258 potential articles, after excluding COVID-related CVST, potential duplicates, multiple reports of the same dataset, redundant and incomplete reports, 41 eligible studies on 552 patients [5,11,13-51] were retrieved (Figure 1).

Three were systematic reviews or case series, consisting of 213 patients from the European Medicines Agency [34] and 197 from the UK [38,39]. Another multicenter registry from Germany also described CVST as a manifestation of the HIT-like VITT syndrome [42]. Basic characteristics of the patient population appear in Table 1.

Although CVST occurred after all type of vaccines, it was much more frequent after ChAdOx1 nCoV-19 shots. patients were free of chronic cardiovascular disease, conventional risk factors, or predisposing pro-thrombotic genetic conditions, often were younger than 50 years of age. 


\section{Literature data search}

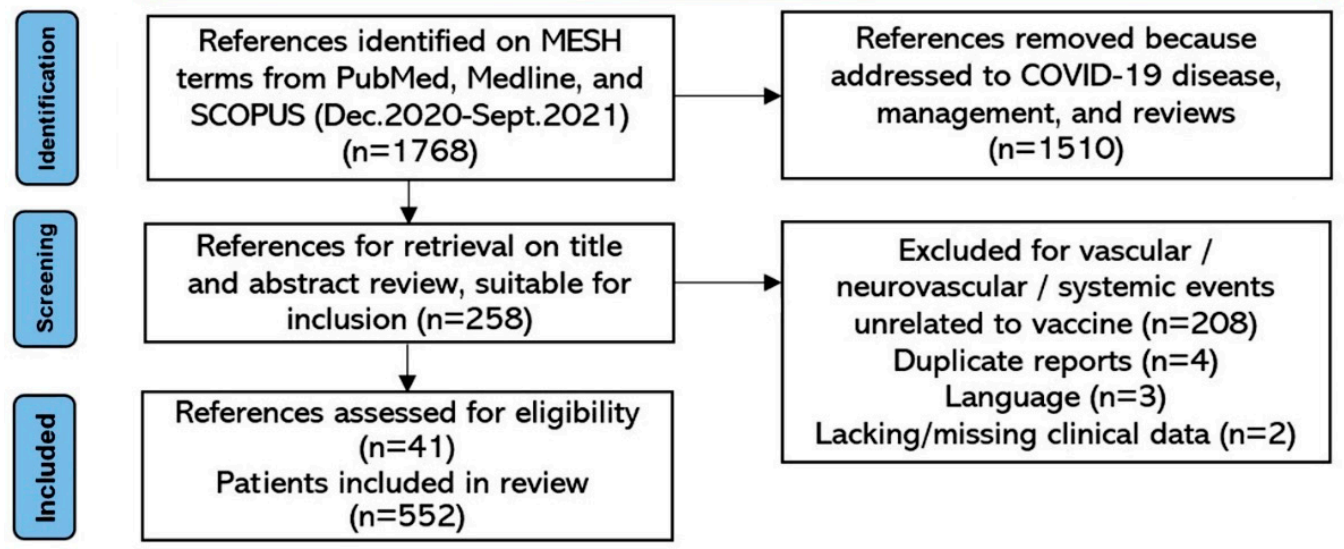

Figure 1. Flow diagram for study selection.

Conversely, thrombophilia mutation(s), antiphospholipid antibodies, C-protein/S-protein deficiency, Leiden factor, were reported in mRNA vaccine recipients, corresponding to $10 \%$ of the whole study population.

Some CVST patients presented twice in the emergency department after the first shot, because of atypical or misinterpreted symptoms, especially from January to March 2021, when VITT syndrome had not yet been recognized. However, patients experienced a complex clinical picture, in most cases requiring a multispecialty problem-solving team, with neurologists, neurosurgeons, vascular surgeons, and intensivists.

\subsection{Demographic and Clinical Characteristics}

Cerebral venous sinus thrombosis occurred in 382 women and 170 men (W/M ratio 2.25), with a median age of 44 years (range 18-84) (Figure 2). The median time of symptom onset from vaccination (first shot in $99 \%$ of cases) was 9 days (range $2-42$ ).

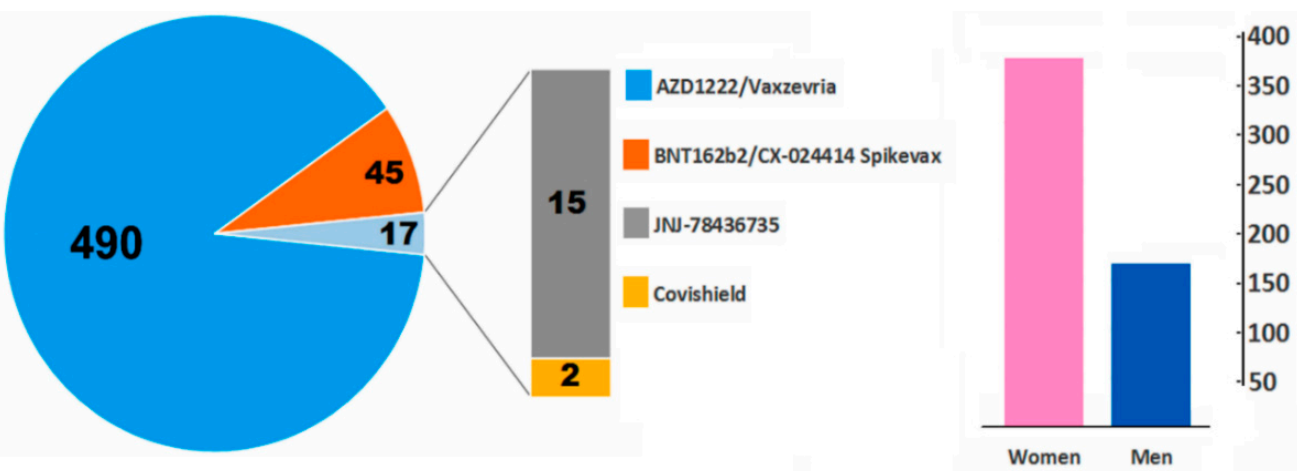

Figure 2. Summary of included cases $(n=552)$ with CVST after vaccination. The women $/ \mathrm{men}$ ratio was 2.25.

Unrelenting headache, nausea, vomiting, dizziness, seizure, were frequently complained by alert and oriented cases on arrival to the hospital. Some patients, however, presented in the emergency department with a severe neurological syndrome such as hemorrhagic stroke, cerebral edema/infarction, hematomas (hereinafter all these termed brain injury), often in a comatose setting.

\subsection{Site of Thrombosis}

Thirty-seven studies ( $n=155$ patients) clearly described the location of blood clots within the cerebral circulation. Thrombi were detected in almost all the main venous channels (Figure 3), but predominantly transverse and sigmoid sinuses, with a left-side 
predominance ( $53 \%$ vs. $47 \%$ of right-side, $p=$ NS). Five percent of patients showed bilateral transverse, sigmoid, or cerebral vein thrombosis.

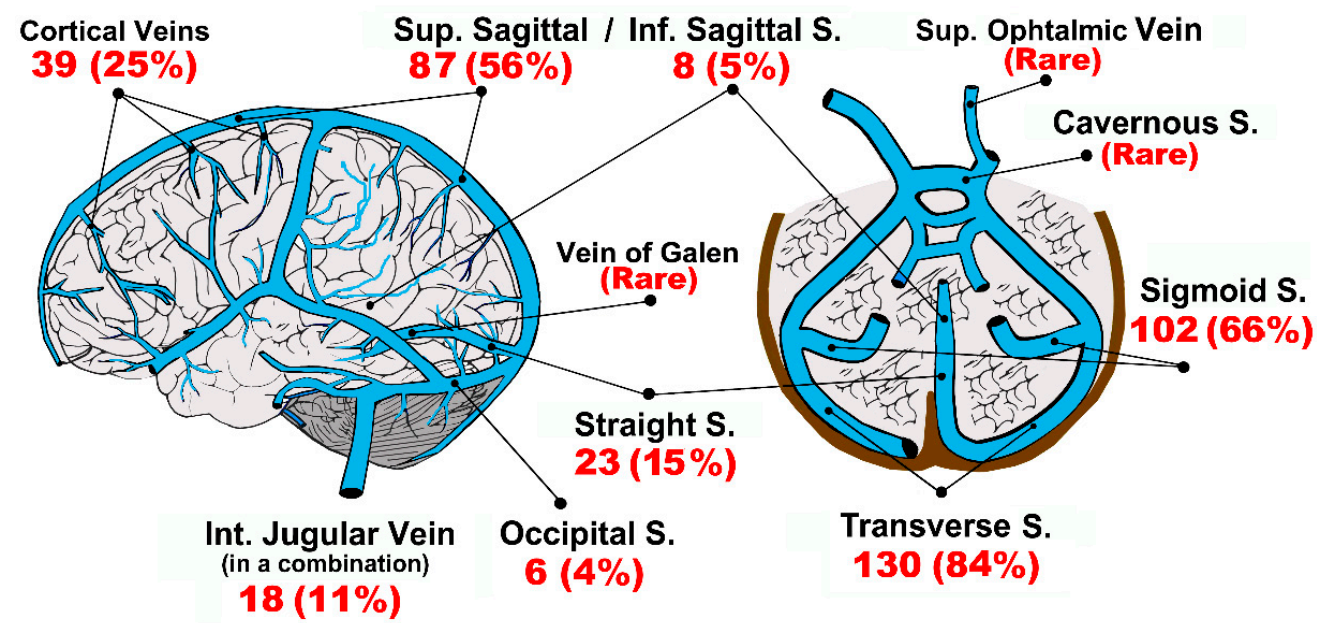

Figure 3. Representation of the anatomy of cerebral veins, site(s) and rates of thrombus formation ( $n=155$ patients). Most patients were found to have clots in more than a single vessel. Abbreviations, S.: Sinus/sinuses; Inf.: Inferior; Int.: Internal; Sup.: Superior.

Table 1. Patient population from 41 studies from all over the world.

\begin{tabular}{|c|c|c|c|c|c|}
\hline Author & Females & Males & Age * & Country & Vaccine \\
\hline (1) Esba et al. [15] & 1 & 1 & 50 & Saudi Arabia & AZD1222 (ChAdOx1 nCoV-19) \\
\hline (2) Aladdin et al. [16] & 1 & - & 36 & Saudi Arabia & AZD1222 (ChAdOx1 nCoV-19) \\
\hline (3) Bayas et al. [17] & 1 & - & 55 & Germany & AZD1222 (ChAdOx1 nCoV-19) \\
\hline (4) Bjørnstad-Tuveng et al. [18] & 1 & - & 30 & Norway & AZD1222 (ChAdOx1 nCoV-19) \\
\hline (5) Choi et al. [19] & - & 1 & 33 & Korea & AZD1222 (ChAdOx1 nCoV-19) \\
\hline (6) Crossette-Thambiah et al. [20] & 4 & - & 44 & UK & AZD1222 (ChAdOx1 nCoV-19) \\
\hline (7) D'Agostino et al. [11] & 1 & - & 54 & Italy & AZD1222 (ChAdOx1 nCoV-19) \\
\hline (8) De Michele et al. [21] & 2 & - & 56 & Italy & AZD1222 (ChAdOx1 nCoV-19) \\
\hline (9) Dias et al. [22] & 2 & - & 57 & Portugal & BNT162b2 \\
\hline (10) Dutta et al. [23] & - & 1 & 51 & India & Covishield \\
\hline (11) Fanni et al. [24] & 1 & - & 58 & Italy & AZD1222 (ChAdOx1 nCoV-19) \\
\hline (12) Franchini et al. [25] & - & 1 & 50 & Italy & AZD1222 (ChAdOx1 nCoV-19) \\
\hline (13) Gattringer et al. [26] & 1 & 1 & 33 & Austria & AZD1222 (ChAdOx1 nCoV-19) \\
\hline (14) Geeraerts et al. [27] & 2 & - & N.A. & France & AZD1222 (ChAdOx1 nCoV-19) \\
\hline (15) George et al. [28] & 1 & - & 40 & Colorado (US) & JNJ-78436735 (Ad26.COV2) \\
\hline (16) Gessler et al. [29] & 3 & - & 47 & Germany & AZD1222 (ChAdOx1 nCoV-19) \\
\hline (17) Graf et al. [30] & - & 1 & 29 & Germany & AZD1222 (ChAdOx1 nCoV-19) \\
\hline (18) Greinacher et al. [5] & 9 & 1 & 36 & Germany/Austria & AZD1222 (ChAdOx1 nCoV-19) \\
\hline (19) Ikenberg et al. [31] & 1 & - & 30 & Germany & AZD1222 (ChAdOx1 nCoV-19) \\
\hline (20) Jamme et al. [32] & 1 & - & 69 & France & AZD1222 (ChAdOx1 nCoV-19) \\
\hline (21) Kotal et al. [33] & 1 & - & 32 & India & Covishield \\
\hline (22) Krzywicka et al. [34] & 139 & 48 & 46 & EMA survey & AZD1222 (ChAdOx1 nCoV-19) \\
\hline (22) Krzywicka et al. [34] & 20 & 6 & 56 & EMA survey & BNT162b2/CX-024414 Spikevax \\
\hline (23) Lin et al. [35] & - & 1 & 52 & Taiwan & AZD1222 (ChAdOx1 nCoV-19) \\
\hline
\end{tabular}


Table 1. Cont.

\begin{tabular}{|c|c|c|c|c|c|}
\hline Author & Females & Males & Age * & Country & Vaccine \\
\hline (24) Mazzeo et al. [36] & 1 & 1 & 50 & Italy & AZD1222 (ChAdOx1 nCoV-19) \\
\hline (25) Mehta et al. [13] & - & 2 & 28 & United Kingdom & Vaxzevria \\
\hline (26) Muir et al. [37] & 1 & - & 48 & Nebraska (US) & JNJ-78436735 (Ad26.COV2) \\
\hline (27) Pavord et al. [38] & 57 & 45 & 48 & UK (MC) & AZD1222 (ChAdOx1 nCoV-19) \\
\hline (28) Perry et al. [39] & 54 & 41 & 53 & UK (MC) & AZD1222 (ChAdOx1 nCoV-19) \\
\hline (29) Pomara et al. [40] & 1 & - & 39 & Italy & AZD1222 (ChAdOx1 nCoV-19) \\
\hline (30) Schultz et al. [41] & 4 & 1 & 39 & Norway & AZD1222 (ChAdOx1 nCoV-19) \\
\hline (31) Schulz et al. [42] & 29 & 8 & 45 & Germany (MC) & AZD1222 (ChAdOx1 nCoV-19) \\
\hline (31) Schulz et al. [42] & 6 & 2 & 45 & Germany (MC) & BNT162b2 \\
\hline (32) See et al. [14] & 12 & - & 46 & VAERS (US) & JNJ-78436735 (Ad26.COV2) \\
\hline (33) Smadja et al. [43] & 3 & 4 & 34 & France & AZD1222 (ChAdOx1 nCoV-19) \\
\hline (33) Smadja et al. [43] & 4 & -- & 34 & France & BNT162b2 \\
\hline (33) Smadja et al. [43] & 3 & - & 33 & France & CX-024414 Spikevax \\
\hline (34) Syed et al. [45] & - & 1 & 45 & Pennsylvania (US) & CX-024414 Spikevax \\
\hline (35) Suresh et al. [46] & 1 & - & 29 & UK & AZD1222 (ChAdOx1 nCoV-19) \\
\hline (36) Tølbøll Sørensen et al. [44] & 1 & - & 30 & Denmark & AZD1222 (ChAdOx1 nCoV-19) \\
\hline (37) Vayne et al. [47] & 5 & 1 & 44 & France (MC) & AZD1222 (ChAdOx1 nCoV-19) \\
\hline (38) Wiedmann et al. [48] & 5 & - & 39 & Norway & AZD1222 (ChAdOx1 nCoV-19) \\
\hline (39) Wolf et al. [49] & 3 & - & 36 & Germany & AZD1222 (ChAdOx1 nCoV-19) \\
\hline (40) Yahyavi-Firouz-Abadi et al. [50] & 1 & - & 30 & Maryland (US) & JNJ-78436735 (Ad26.COV2) \\
\hline (41) Zakaria et al. [51] & - & 1 & 49 & Malaysia & BNT162b2 \\
\hline
\end{tabular}

* Median value (from case series) or single patient's age (years). Abbreviations, E.M.A.: European Medicines Agency; M.C.: Multicenter Study/Registry; N.A.: not available; U.K.: United Kingdom; U.S.: United States (of America); V.A.E.R.S.: Vaccine Adverse Event Reporting System.

Internal jugular veins thrombosis was detected in 18 patients, very often in a combination with homolateral transverse and sigmoid sinuses. However, carotid/jugular ultrasound was performed only in a small number of patients.

Multisite systemic venous thromboses were observed in 141/155 patients (91\%), mainly involving abdominal districts (mesenteric, hepatic and splanchnic), pulmonary arteries (thrombo-embolism), and inferior limbs. Two patients from De Michele et al.'s publication [21] were recognized to have a combination of cerebral artery and vein occlusion. As shown in Table 2, 32/41 studies met the criteria for VITT $[5,8,41,49,52]$ only in a proportion of patients.

Table 2. Summarized criteria for VITT syndrome from our CVST patient population (32/41 studies).

\section{Criteria *}

COVID vaccine $4-42$ days prior to symptom onset

Any venous or arterial thrombosis

Thrombocytopenia

Positive PF4-polyanion-Ig by ELISA

D-dimer $>4$ times upper limit of normal

* Criteria for vaccine-induce thrombotic thrombocytopenia (VITT), according to American Society of Hematology Guidelines (https:/ / www.hematology.org/ covid-19/vaccine-induced-immune-thrombotic-thrombocytopenia, accessed on 30 November 2021); Greinacher et al. [5]; Shultz et al. [41]; Sharifian-Dorche et al. [53]; Rizk et al. [52]; and Lee et al. [54].

\section{Proportion of Patients}

$98 \%$

$100 \%$

$61 \%$

$47 \%$

$80 \%$ 


\subsection{Histopathological Findings}

Only scant information was available on histopathological findings in CVST patients. Postmortem examination was performed in the study of Wiedmann et al. [48]. Aside from the description of hemorrhagic areas, one patient was found to have mixed red-white clot formation in the transverse and sigmoid sinus, as well as remnants of white clots attached to the endothelium in the sagittal sinus. Microscopy confirmed multiple arteriolar thrombi in organization. Fibrin aggregates were also observed within the small veins of lung lobes and of the myocardium as well. Another patient showed extracerebral thrombi were rich in platelets, fibrin, leukocytes, and abundant monocytes attached to the endothelium, but disorganized. Of note, those patients had no pre-existing organ disease.

Fibrin thrombi in the cortical vessels and microthrombi in the capillaries of choroid plexuses were reported by Fanni et al. [24]. Those findings were associated with intestinal wall hemorrhagic necrosis, venous congestion in various organs. Micro-thrombi were also seen in the lumen of dilated pulmonary capillary vessels associated with edema, cellular debris, as in the early exudative phase of acute respiratory distress syndrome.

Multivessel thrombi were also seen within the cardiac veins and capillaries, both in the subepicardial fat and deep myocardium, as well as in the vasa vasorum of the arterial wall of the abdominal aorta.

Figure 4 illustrates a well-organized thrombus with centrally located red blood cells in hemorrhagic areas and surrounding fibrin accumulation in a Sicilian patient with CVST. Microthrombi were also found within the small vessels at the periphery of a large thrombus formation. Interspersed leukocytes and mononuclear infiltration were also present, with large endothelial desquamation.

Tissue inspection by Pomara et al. [40] revealed the presence of thrombi in the smallmedium-sized vessels and increased inflammatory infiltrates. Immunohistochemical analyses highlighted the vascular and peri-vascular expression of adhesion molecules such as VCAM-1, as well as the presence of CD66b+, CD163+, and CD61+-activated inflammatory cells (especially leukocytes, both polymorphonuclear cells and monocytes/macrophages and megakaryocytes), suggesting the activation of the innate immune system. Multiple organ injury was also due to the deposition of pro-inflammatory molecules $(\mathrm{C} 1 \mathrm{r}, \mathrm{C} 4 \mathrm{~d})$ in the interstitial spaces.

\subsection{Management and Outcomes}

Analysis of in-hospital management was not the aim of the present analysis; notably other studies have addressed this aspect [14,34,38,42,55-57]. Herein, we summarize the main treatment provided to patients. Intravenous immunoglobulins (Igs) were first administered to most patients at a mean dose of $1 \mathrm{~g} / \mathrm{kg}[5,10,14,34]$. Anticoagulants (argatroban, fondaparinux, etc.) were also given, except for patients with intracranial bleeding. In general, heparin use was discouraged because of the potential of bursting the PF4-polyanion immunogenicity, according to a shared pathomechanism between HIT and VITT $[5,10]$. Platelet transfusion was discouraged based on based on lack of information on benefit in patients with HIT [7,8] or disseminated intravascular coagulation (DIC) [58].

Overall, positive outcomes were reported in no-stroke patients. Advanced endovascular procedures such as rheolysis, flushing, and aspiration with $50 \%$ saline solution with contrast medium [49] or mechanical thrombectomy [19] were attempted throughout the jugular vein.

As suggested by the current European Stroke guidelines [57], decompressive neurosurgery was performed in patients with parenchymal lesions, edema, and impending herniation. Brain injury was observed in 174 patients (32\%).

However, the clinical course was comprehensively described in $426 / 552$ patients (77\%). Two hundred and sixty-eight in this subgroup (63\%) were discharged from the hospital in a good clinical condition, at times with variable neurological sequelae, whereas 158 died $(37 \%) ; 152$ of these deaths were in the ChAdOx1nCoV-19 group, and were related to stroke injury and/or thrombocytopenia (Figure 5). 

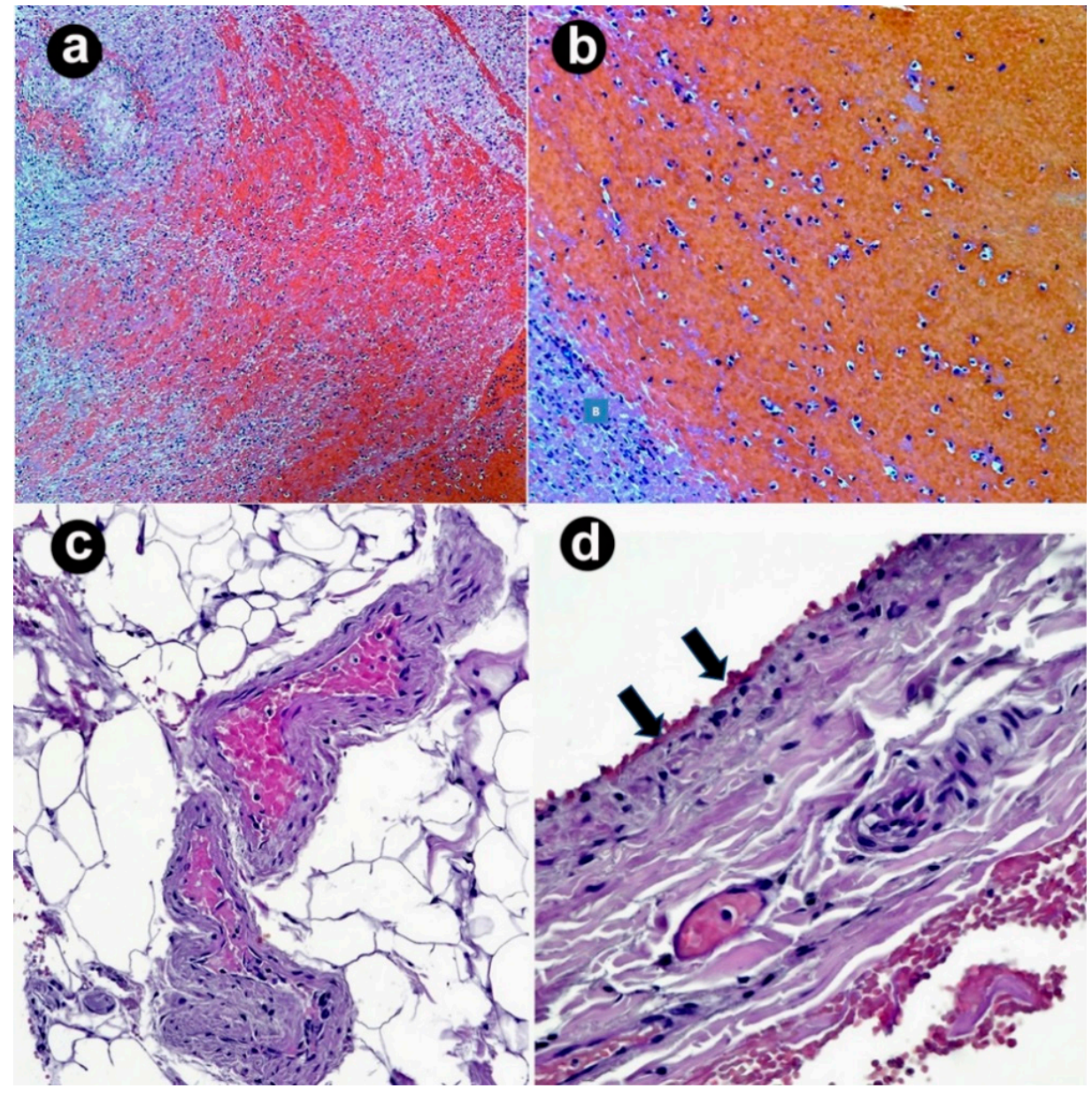

Figure 4. Histopathological findings in a female patient with CVST (hematoxylin-eosin). (a) Wellorganized thrombus with centrally located red blood cells/hemorrhagic areas and surrounding fibrin accumulations $(100 \times$ original magnification); (b) leukocytes are variably interspersed $(200 \times$ original magnification); (c) microthrombi in small vessels at the periphery of the large thrombus (400× original magnification); (d) endotheliitis with mononuclear infiltration and areas of endothelial desquamation (arrows) (400× original magnification).

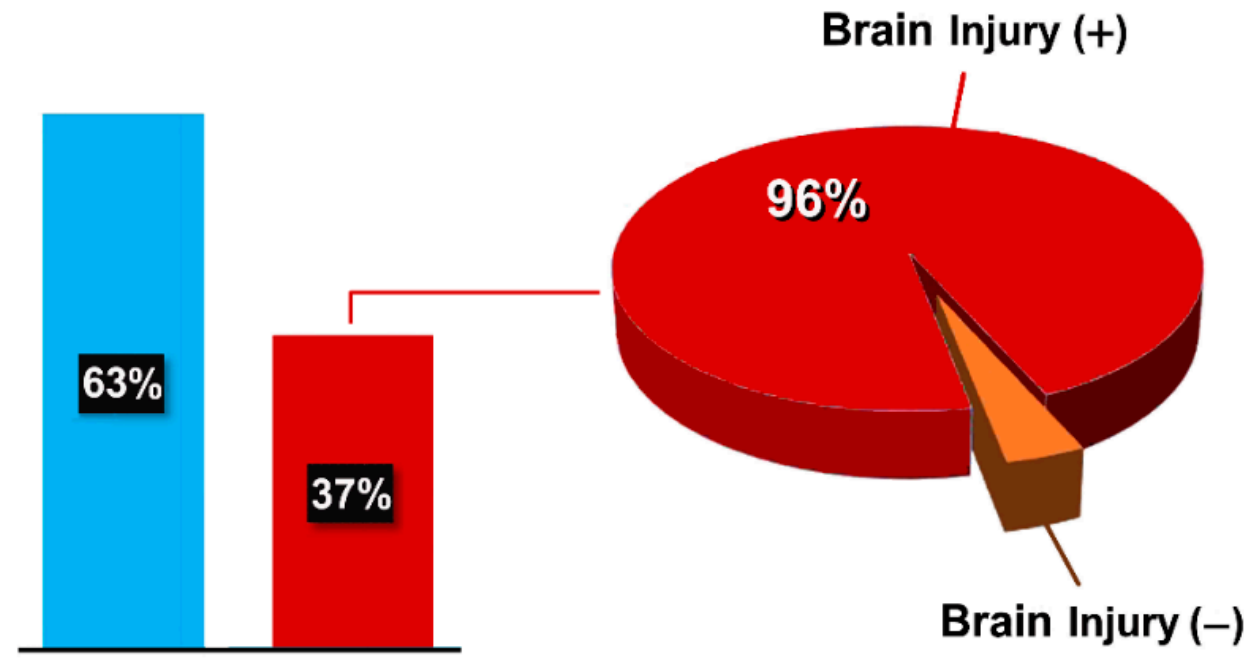

\section{Alive Deceased}

Figure 5. Clinical outcome in the patient population $(n=426)$. Brain injury was described as cerebral edema, hematoma, hemorrhage, and/or infarction, often associated with thrombocytopenia. 


\section{Discussion}

To the best of our knowledge, this is the largest case series analysis of CVST following COVID-19 vaccination since December 2020, the first COVID-19 vaccines received emergency use authorization in the Western countries, until September 2021. Although very dramatic in some patents, CVST was confirmed as a rare clinical event, considering the high number of doses of vaccine administered worldwide.

In general, CVST has been described as a form of vascular disease occasionally affecting young women with the same risk factors as in other forms of peripheral venous thrombosis [57-60]. As of early April 2021, online published index-cases were from Europe and UK $[5,11,13,25,42]$, but many other patients were reported afterwards.

It was difficult to provide the true incidence of CVST in a real-world vaccinated population, also because suspected, probably, or not recognized cases may have never been published. Studies on the US general population established a rate of $0.5-0.8$ per $1,000,000$ individuals (Afro-Americans more likely) in a 10-year period, before the COVID19 pandemic $[9,59,60]$. More recently, a significantly higher rate (one case per 100,000 people) was reported among recipients of the ChAdOx1 nCoV-19 vaccine (especially women) in an editorial by Ropper and Klein [60] and by the EMA (one per 250,000 people) [61].

More dramatic rates have been described by Pottegård et al. from Danish and Norwegian registries, with one case in $40,160(24.9$ per $1,000,000)$ [62]. In this regard, however, discrepancies in delivering vaccination among countries should also be considered, especially at early vaccination campaign, as vaccines were not easily available $[60,61]$.

From the findings of the present study, it appears that mRNA vaccines and the recent Vaxzevria (just one patient in our data set) are safer than the native ChAdOx1 nCoV-19 vaccine, with respect to the occurrence of CVST.

Of interest, similar events also occurred in COVID-19 patients [63]. In a retrospective cohort study, CVST was found in 40-45 patients per 1,000,000 infected [9]. The more serious the infection, there was more likelihood of vascular thrombotic complications as reported by Piazza et al. [64], with 35\% incidence in hospitalized vs. $2.6 \%$ non-hospitalized patients in the intensive care unit. Therefore, some pathophysiological similarities can be postulated to cause CVST in both infected and vaccinated patients [36,58,60-64].

Historically, prognosis in CVST is strictly related to its specific clinical setting, quick diagnosis, and treatment protocols. The mortality rate has been reported to vary from 5 to $15 \%$ and more than two-thirds of patients make a full recovery $[9,57,59,60,65,66]$.

Unfortunately, mortality rates in our data set were very high among complicated patients, in whom brain injuries, whether associated with severe thrombocytopenia, were strong prognosticators. Anti-thrombotic treatment was more effective in uncomplicated patients.

\subsection{Pathophysiological Mechanism(s) of Thrombosis}

At the time of this review, CVST is considered a VITT framework. However, in the study of Pavord et al. from the UK [38], anti-PF4 antibodies were present in 198 of 220 patients (90\%) with definite/probable VITT, and $81 \%$ of those who died. Only 17 specialist laboratories in the UK were able to perform the HIT-ELISA method for testing anti-PF4 antibodies. In the studies included in our review, such laboratories were hardly accessible at least until May 2021, thus explaining anti-PF4-positivity only in half of patients. Of clinical interest, however, a recent study by Terpos et al. demonstrated that antibodies against PF4 were found in two-thirds of ChAdOx1 $\mathrm{nCoV}-19$ recipients irrespective of clinical manifestation of thrombosis, to some extent related to COVID-19 virus-neutralizing circulating antibodies [67]. These data, if confirmed, may raise questions regarding the genetic immunity problem prior to the vaccine. Based on inherent studies, position papers, and current findings [3,52,57-61,65], the main predisposing factors for CVST after COVID19 vaccination, primarily adenoviral vector, are summarized in Table 3. 
Table 3. Predisposing conditions for CVST to consider in people undergoing (adenoviral vector) vaccination (based on former studies).

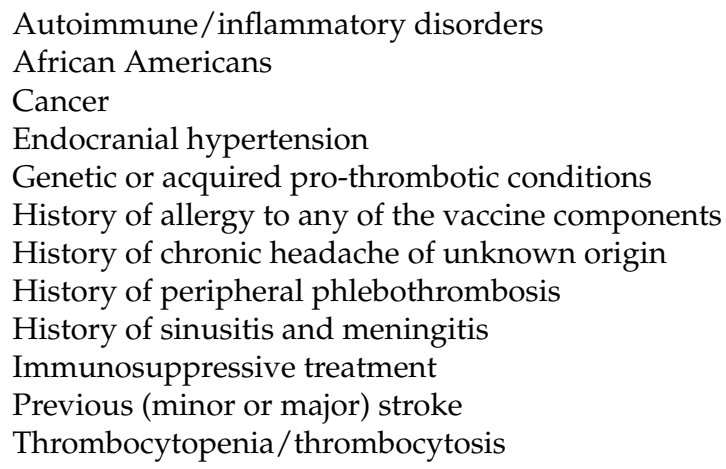

Of note, most CVST patients in this review had no typical prothrombotic risk factors, and this contributed to the media reports on such unexpected outcomes.

As aforementioned, blood clots can be triggered by abnormal immunogenicity of PF4-polyanion complexes. PF4 is a protein present in the a-granules of platelets that can quickly bind either exogenous or endogenous polyanions such as heparin, bacterial or virus proteins, or glycosaminoglycans of the vascular cells. The PF4/polyanion pair act as autoantigen-inducing antibodies of the IgG class. On the other hand, PF4-polyanion-IgG complexes can also be detected in 3-5\% of healthy subjects, with a risk of platelet aggregation via FcRIIa/CD32 receptors on their surface, which could be a common pathway for VITT, HIT, or DIC syndromes $[4,5,7,8,16,57,58]$. Similarly, spike proteins during COVID-19 infection have also been demonstrated to cause PF4 degranulation, platelet aggregation, and thrombosis $[4,64,65]$.

Although CVST was detected mainly among women younger than 60 years, 169 men also showed the same complication. Coagulative disorders in pregnant and puerperal women were found to cause CVST as a manifestation of DIC/HIT-like syndromes. Hormonal alterations and thromboplastin-like material from the amniotic fluid have been suggested as potential triggers of vascular thrombosis [7-9,57,58]. However, questions regarding male patients remain open. Antiphospholipid antibody syndrome, factor $\mathrm{V}$ Leiden disorders, protein $\mathrm{S}$ and/or protein $\mathrm{C}$ deficiency, prothrombin gene mutation, and hyper-homocysteinemia may be considered in both women and men, although these features have been found in approximately $30 \%$ of CVST patients in previous studies $[9,57,68]$. Oral contraceptives, drugs, cancer, chemotherapy, leukemia, polycythemia, neurological diseases (cranial traumas, meningiomas, neurosurgical procedures, bacterial meningitis, hydrocephalies) can also emblematize hazardous conditions $[59,60,68]$.

\subsection{Cerebral Venous Compartment}

The whys and wherefores of CVST that may lead to cerebral tissue injury have been described previously $[10,53,56,57,59,60]$. In the first clotting phase, occlusion is incomplete, the venular pressure gradually increases, capillary exchanges start failing, cerebrospinal fluid absorption relents, and edema with tissue ischemia occurs. As thrombi become occlusive or disseminated, the arteriolar and venular wall, and capillaries as well, become highly friable and bleeding. The reasons why thrombosis often occurs in the cerebral venous vessels have been debated; this issue needs to be studied. Randomness is not enough to explain such unusual phenomena $[57,61,62]$.

We have learned from Virchow's studies that at least three components are needed for red clot formation within the venous system [69]. Given that PF4-immune complexes are important clues for the VITT syndrome $[5,8,13,55,57]$, other cofactors such as slow blood flow velocity and endothelial disease should also be encountered for thrombogenicity [69-71]. We do not know whether blood flow slowing may occur within cerebral veins in the absence of anatomical anomalies. However, we are aware of the fact that even apparently 
healthy people (women first) suffer from inherited venous hypotonia [72] that may result in subclinical phlebostasis. In our patients with blood clot site description, thrombosis chiefly occurred within transverse, sigmoid, and superior sagittal sinuses, confirming previous studies in both adults and children [59,64]. These findings would suggest their flat, transversal, pathway might be implicated in thrombogenesis, together with other predisposing features. Studies have demonstrated that extracranial compression or anomaly of the internal jugular vein concurs to red cell sludging and thrombosis in intracranial tributary veins $[59,73,74]$. Jugular vein pressure, as an expression of the right atrial pressure, was recently reported as being predictive of central venous congestion [75].

\subsection{Allergic Reactions}

Anaphylaxis represents another important issue to consider. The immune system produces neutralizing antibodies to membrane proteins of pathogens, such as adenoviral vectors, spike proteins, and mRNA-stimulated recipient cells. Lymphocytes and neutrophil extracellular traps (NETs) are inflammatory modulators and can activate the coagulation cascade through factor VII and other tissue factors, possibly causing VITT in both infected and vaccinated individuals. Furthermore, genetic polymorphism, high endothelial CD32 receptor' density, and/or different vascular affinity for such immune complexes may be further cofactors of the immunomodulated vasculitis and thrombosis $[2,4,36,76-78]$, as confirmed by immuno-histochemical post-mortem examinations showing the coexistence of multisite vessel thrombosis and cell-mediated endothelial inflammation [24,40,48].

Thrombosis may be the consequence of allergic reactions to vaccine excipients, often occurring days after the shot. These are usually antibody independent, cell mediated stemming from T-cell activation, as well as monocyte and macrophage responses to the sensitizer $[2,77,78]$. Vaccines containing thimerosal, aluminum, polyethylene glycol, polysorbate 80 , and other molecules can determine either immediate or delayed hypersensitivity. Platelet's surface shows a high affinity for IgE via FcRI receptors and low-affinity IgE FcRII/CD23 receptors, and the subsequent cytokine storm closely resembles the pathophysiology of Kounis syndrome [2,4]. Both ChAdOx1 nCov-19 and Ad26.COV2 vaccines contain polysorbate 80 , a synthetic nonionic surfactant additive that may convey severe allergic reactions and vascular thrombosis. Of clinical concern, polysorbate 80 also breaks the blood-brain barrier, enhances membrane permeability, and facilitates the migration of drugs or other substances from the blood compartment into the brain $[2,78,79]$.

\subsection{Other Hypotheses}

There are many unsolved issues on COVID-19 disease and related inflammatory reaction injuries determining clinical phenotype among infected individuals. The role of neutralizing antibodies, B- and T-cells, white cells, platelets, interleukins, and interferon represent a myriad of features for preventing organ disease infection. Immunopathogenesis of both infection- and vaccine-related adverse effects is continuously under investigation. Acute respiratory distress syndrome may be caused by heterogeneous events, including non-infectious agents. It is a recognized notion that inflammation can be triggered even by small substances derived from injured, post-traumatic and/or post-vaccine, targeted cells (either infected or non-infected). These pathogen-like substances can lead to unusual clinical pictures such as the multisystem inflammatory syndrome in children or multisite thrombogenic syndrome in adults $[79,80]$.

To explain all clinical aspects of immunological diseases, new concepts of immunopathogenesis are now accepted, in which not solely pathogens themselves but also infectionassociated immune-mediated responses and/or vaccine-induced complications (vascular thrombosis) may have a 'limited' ability to cause host cell injury. It is now known that the host immunity reacts to not only smaller substances from the infectious agent, including toxins and pathogen-associated molecular patterns (PAMPs), but also to pro-inflammatory proteins and peptides produced by the injured (non-infected) host cells, known as damageassociated molecular patterns (DAMPs). It has been postulated that the main function 
of the host immune/repair system at the molecular level is to control the release of toxic substances by a better identification of inflammatory proteins and peptides, based on their size and biochemical characteristics (the protein-homeostasis-system hypothesis) [80-83].

\section{Study Limitations}

There are some limitations in the present narrative review. We included studies afterthorough review, some studies could have been missed. A few studies we considered as original descriptions were also included in subsequent reviews from the same region or study group, and it was difficult to extrapolate these duplicates from inclusive and larger case series.

This research was not for a pharmaco-vigilance purpose, so the event rates were just hypothesized based on previous studies. In fact, stratification of rare events among larger populations can be inaccurate unless all events had been noticed by the Health Authority. The best way to evaluate the CVST risk should be by performing a pair-matching analysis on vaccinated vs. unvaccinated people in a 1:1 ratio, according to their demographic and clinical characteristics. As mentioned, in early 2021, there was slight clinical awareness on post-vaccine syndromes, so some cases could have been missed. At present, this represents a hypothesis-generating study, and further investigation on chemical and pharmacological properties, production, and delivery of vaccines is encouraged.

\section{Conclusions}

Vaccines remain the best way to fight the current COVID-19 pandemic. The present study likely confirmed the rare, often dramatic, occurrence of CVST following (adenovirus vector) vaccine shots. The incidence of thrombus formations was 2.25 -fold higher in women of childbearing age than in men, and systemic multivessel disease was detected in $>90 \%$ of cases. Transverse and sigmoid venous sinuses were preferred intracerebral locations for thrombosis, and poor outcomes were reported in patients with brain injury, such as intracranial bleeding, whether in association with thrombocytopenia. Although thrombogenic mechanisms are still under discussion within the scientific community, currently available histopathological findings indicate an underlying prothrombotic immune microand macro-vasculitis.

Author Contributions: Conceptualization, C.d.G.; methodology, C.d.G., L.C. and N.G.K.; validation, C.d.G., L.C., G.C., P.P.B., G.F., I.K., A.T.M. and N.G.K.; formal analysis, C.d.G., L.C., G.C., A.T.M., J.L.M. and N.G.K.; investigation, C.d.G., L.C., A.T.M., A.N. and A.I.; writing-original draft preparation, C.d.G.; writing—review and editing, C.d.G., G.C. and N.G.K.; revision and check, C.d.G., G.C., J.L.M., and N.G.K. All authors have read and agreed to the published version of the manuscript.

Funding: This research received no external funding.

Institutional Review Board Statement: This review study was conducted in accordance with the Declaration of Helsinki. Information were achieved by already published studies and summarized anonymously. The study did not require ethical approval.

Informed Consent Statement: Informed consent was obtained, if applicable, from the authors of each cited article. Findings were reported anonymously.

Conflicts of Interest: The authors declare no conflict of interest.

\section{References}

1. Spellberg, B.; Nielsen, T.B.; Casadevall, A. Antibodies, immunity, and COVID-19. JAMA Int. Med. 2021, 81, 460-462. [CrossRef]

2. Kounis, N.G.; Koniari, I.; de Gregorio, C.; Velissaris, D.; Petalas, K.; Brinia, A.; Assimakopoulos, S.F.; Gogos, C.; Kouni, S.N.; Kounis, G.N.; et al. Allergic reactions to current available COVID-19 vaccinations: Pathophysiology, causality, and therapeutic considerations. Vaccines 2021, 9, 221. [CrossRef] [PubMed]

3. Kantarcioglu, B.; Iqbal, O.; Walenga, J.M.; Lewis, B.; Lewis, J.; Carter, C.A.; Singh, M.; Lievano, F.; Tafur, A.; Ramacciotti, E. An update on the Pathogenesis of COVID-19 and the reportedly rare thrombotic events following vaccination. Clin. Appl. Thromb. Hemost. 2021, 27, 14. [CrossRef] [PubMed] 
4. Kounis, N.G.; Koniari, I.; de Gregorio, C.; Assimakopoulos, S.F.; Velissaris, D.; Hung, M.Y.; Mplani, V.; Saba, L.; Brinia, A.; Kouni, S.N.; et al. COVID-19 disease, women's predominant non-heparin vaccine-induced thrombotic thrombocytopenia and Kounis Syndrome: A passepartout cytokine storm interplay. Biomedicines 2021, 9, 959. [CrossRef] [PubMed]

5. Greinacher, A.; Thiele, T.; Warkentin, T.E.; Weisser, K.; Kyrle, P.A.; Eichinger, S. Thrombotic thrombocytopenia after ChAdOx1 nCov-19 vaccination. N. Engl. J. Med. 2021, 384, 2092-2101. [CrossRef]

6. Oldenburg, J.; Klamroth, R.; Langer, F.; Albisetti, M.; von Auer, C.; Ay, C.; Korte, W.; Scharf, R.E.; Pötzsch, B.; Greinacher, A. Diagnosis and management of vaccine-related thrombosis following astrazeneca COVID-19 vaccination: Guidance statement from the GTH. Hamostaseologie 2021, 41, 184-189.

7. Kelton, J.G. Heparin-induced thrombocytopenia. Haemostasis 1986, 16, 173-186.

8. Greinacher, A. Heparin-induced thrombocytopenia. Pathogenesis and treatment. Thromb. Haemost. 1999, 82, 148-156. [CrossRef]

9. Taquet, M.; Husain, M.; Geddes, J.R.; Luciano, S.; Harrison, P.J. Cerebral venous thrombosis and portal vein thrombosis: A retrospective cohort study of 537,913 COVID-19 cases. E Clin. Med. 2021, 39, 101061. [CrossRef]

10. Saposnik, G.; Barinagarrementeria, F.; Brown, R.D., Jr.; Bushnell, C.D.; Cucchiara, B.; Cushman, M.; de Veber, G.; Ferro, J.M.; Tsai, F.Y.; American Heart Association Stroke Council and the Council on Epidemiology and Prevention. Diagnosis and management of cerebral venous thrombosis: A statement for healthcare professionals from the American Heart Association/American Stroke Association. Stroke 2011, 42, 1158-1192.

11. D'Agostino, V.; Caranci, F.; Negro, A.; Piscitelli, V.; Tuccillo, B.; Fasano, F.; Sirabella, G.; Marano, I.; Granata, V.; Grassi, R.; et al. A Rare Case of cerebral venous thrombosis and disseminated intravascular coagulation temporally associated to the COVID-19 vaccine administration. J. Pers. Med. 2021, 11, 285. [CrossRef] [PubMed]

12. European Medicines Agency: Signal Assessment Report on Embolic and Thrombotic Events (SMQ) with COVID-19 Vaccine (ChAdOx1-S-COVID-19 Vaccine AstraZeneca (Other Viral Vaccines). Available online: https://www.ema.europa.eu/en/ documents / practical-recommendation (accessed on 31 March 2021).

13. Mehta, P.R.; Apap Mangion, S.; Benger, M.; Stanton, B.R.; Czuprynska, J.; Arya, R.; Sztriha, L.K. Cerebral venous sinus thrombosis and thrombocytopenia after COVID-19 vaccination-A report of two UK cases. Brain Behav. Immun. 2021, 95, 514-517. [CrossRef] [PubMed]

14. See, I.; Su, J.R.; Lale, A.; Woo, E.J.; Guh, A.Y.; Shimabukuro, T.T.; Streiff, M.B.; Rao, A.K.; Wheeler, A.P.; Beavers, S.F.; et al. US Case reports of cerebral venous sinus thrombosis with thrombocytopenia after Ad26.COV2.S vaccination, March 2 to April 21, 2021. JAMA 2021, 325, 2448-2456. [CrossRef] [PubMed]

15. Esba, L.; Al Jeraisy, M. Reported adverse effects following COVID-19 vaccination at a tertiary care hospital, focus on cerebral venous sinus thrombosis (CVST). Exp. Rev. Vaccines 2021, 20, 1037-1042. [CrossRef]

16. Aladdin, Y.; Algahtani, H.; Shirah, B. Vaccine-Induced Immune Thrombotic Thrombocytopenia with disseminated intravascular coagulation and death following the ChAdOx1 nCoV-19 Vaccine. J. Stroke Cerebrovasc. Dis. 2021, 30, 105938. [CrossRef]

17. Bayas, A.; Menacher, M.; Christ, M.; Behrens, L.; Rank, A.; Naumann, M. Bilateral superior ophthalmic vein thrombosis, ischaemic stroke, and immune thrombocytopenia after ChAdOx1 nCoV-19 vaccination. Lancet 2021, 397, e11. [CrossRef]

18. Bjørnstad-Tuveng, T.H.; Rudjord, A.; Anker, P. Fatal cerebral haemorrhage after COVID-19 vaccine. Tidsskr. Den Nor. Legeforening 2021, 141. [CrossRef]

19. Choi, J.K.; Kim, S.; Kim, S.R.; Jin, J.Y.; Choi, S.W.; Kim, H.; Yoo, J.H.; Park, I.S.; Kim, S.R. Intracerebral Hemorrhage due to thrombosis with thrombocytopenia syndrome after vaccination against COVID-19: The First fatal case in Korea. J. Korean Med. Sci. 2021, 36, e223. [CrossRef]

20. Crossette-Thambiah, C.; Pericleous, C.; Asmar, N.; Bomsztyk, J.; Ranger, A.; Shlebak, A.; Ramji, S.; Banerjee, S.; Laffan, M.; Arachchillage, D.J. Clinical and biological features of cerebral venous sinus thrombosis following ChAdOx1 nCov-19 vaccination. J. Neurol. Neurosurg. Psychiatry 2021. [CrossRef]

21. De Michele, M.; Iacobucci, M.; Chistolini, A.; Nicolini, E.; Pulcinelli, F.; Cerbelli, B.; Merenda, E.; Schiavo, O.G.; Sbardella, E.; Berto, I. Malignant cerebral infarction after ChAdOx1 nCov-19 vaccination: A catastrophic variant of vaccine-induced immune thrombotic thrombocytopenia. Nat. Commun. 2021, 12, 4663. [CrossRef]

22. Dias, L.; Soares-Dos-Reis, R.; Meira, J.; Ferrão, D.; Soares, P.R.; Pastor, A.; Gama, G.; Fonseca, L.; Fagundes, V.; Carvalho, M. Cerebral venous thrombosis after BNT162b2 mRNA SARS-CoV-2 vaccine. J. Stroke Cerebrovasc. Dis. 2021, 30, 105906. [CrossRef]

23. Dutta, A.; Ghosh, R.; Bhattacharya, D.; Bhat, S.; Ray, A.; Pandit, A.; Das, S.; Dubey, S. Anti-PF4 antibody negative cerebral venous sinus thrombosis without thrombocytopenia following immunization with COVID-19 vaccine in an elderly non-comorbid Indian male, managed with conventional heparin-warfarin based anticoagulation. Diabetes Metab. Syndr. 2021, 15, 102184. [CrossRef]

24. Fanni, D.; Saba, L.; Demontis, R.; Gerosa, C.; Chighine, A.; Nioi, M.; Suri, J.S.; Ravarino, A.; Cau, F.; Barcellona, D.; et al. Vaccine-induced severe thrombotic thrombocytopenia following COVID-19 vaccination: A report of an autoptic case and review of the literature. Eur. Rev. Med. Pharmacol. Sci. 2021, 25, 5063-5069. [CrossRef]

25. Franchini, M.; Testa, S.; Pezzo, M.; Glingani, C.; Caruso, B.; Terenziani, I.; Pognani, C.; Bellometti, S.A.; Castelli, G. Cerebral venous thrombosis and thrombocytopenia post-COVID-19 vaccination. Thromb. Res. 2021, 202, 182-183. [CrossRef]

26. Gattringer, T.; Gressenberger, P.; Gary, T.; Wölfler, A.; Kneihsl, M.; Raggam, R.B. Successful management of vaccine-induced immune thrombotic thrombocytopenia-related cerebral sinus venous thrombosis after ChAdOx1 nCov-19 vaccination. Stroke Vasc. Neurol. 2021. [CrossRef] [PubMed] 
27. Geeraerts, T.; Montastruc, F.; Bonneville, F.; Mémier, V.; Raposo, N.; Toulouse Vitt Study Group. Oxford-AstraZeneca COVID-19 vaccine-induced cerebral venous thrombosis and thrombocytopaenia: A missed opportunity for a rapid return of experience. Anaesth. Crit. Care. Pain Med. 2021, 40, 100889. [CrossRef] [PubMed]

28. George, G.; Friedman, K.D.; Curtis, B.R.; Lind, S.E. Successful treatment of thrombotic thrombocytopenia with cerebral sinus venous thrombosis following Ad26.COV2.S vaccination. Am. J. Hematol. 2021, 96, E301-E303. [CrossRef]

29. Gessler, F.; Schmitz, A.K.; Dubinski, D.; Bernstock, J.D.; Lehmann, F.; Won, S.Y.; Wittstock, M.; Güresir, E.; Hadjiathanasiou, A.; Zimmermann, J.; et al. Neurosurgical considerations regarding decompressive craniectomy for intracerebral hemorrhage after SARS-CoV-2 vaccination in vaccine induced thrombotic thrombocytopenia-VITT. J. Clin. Med. 2021, 10, 2777. [CrossRef] [PubMed]

30. Graf, T.; Thiele, T.; Klingebiel, R.; Greinacher, A.; Schäbitz, W.R.; Greeve, I. Immediate high-dose intravenous immunoglobulins followed by direct thrombin-inhibitor treatment is crucial for survival in SARS-COVID-19-adenoviral vector vaccine-induced immune thrombotic thrombocytopenia VITT with cerebral sinus venous and portal vein thrombosis. J. Neurol. 2021, 268, 4483-4485.

31. Ikenberg, B.; Demleitner, A.F.; Thiele, T.; Wiestler, B.; Götze, K.; Mößmer, G.; Lingoret, P. Cerebral venous sinus thrombosis after ChAdOx1 nCov-19 vaccination with a misleading first cerebral MRI scan. Stroke Vasc. Neurol. 2021. [CrossRef]

32. Jamme, M.; Mosnino, E.; Hayon, J.; Franchineau, G. Fatal cerebral venous sinus thrombosis after COVID-19 vaccination. Intensive Care Med. 2021, 47, 790-791. [CrossRef] [PubMed]

33. Kotal, R.; Jacob, I.; Rangappa, P.; Rao, K.; Hosurkar, G.; Anumula, S.K.; Kuberappa, A.M. A rare case of vaccine-induced immune thrombosis and thrombocytopenia and approach to management. Surg. Neurol. Int. 2021, 12, 408. [CrossRef]

34. Krzywicka, K.; Heldner, M.R.; van Sánchez Kammen, M.; van Haaps, T.; Hiltunen, S.; Silvis, S.M.; Levi, M.; Kremer Hovinga, J.A.; Jood, K.; Lindgren, E.; et al. Post-SARS-CoV-2-vaccination cerebral venous sinus thrombosis: An analysis of cases notified to the European Medicines Agency. Eur. J. Neurol. 2021, 28, 3656-3662. [CrossRef]

35. Lin, W.; Ko, C.A.; Sung, Y.F.; Chen, Y.C.; Lee, J.T.; Lin, Y.Q.; Lin, Y.K. Cerebral venous sinus thrombosis, pulmonary embolism, and thrombocytopenia after COVID-19 vaccination in a Taiwanese Man: A case report and literature review. Front. Neurol. 2021, 12, 738329. [CrossRef] [PubMed]

36. Mazzeo, A.; Noto, A.; Asmundo, A.; Granata, F.; Galletta, K.; Mallamace, R.; De Gregorio, C.; Puliatti, F.; Fazio, M.C.; Germano, A.; et al. Cerebral venous sinus thrombosis (CVST) associated to SARS-CoV-2 vaccines: Clues for an immunopathogenesis common to CVST observed in COVID-19. Analg. Crit. Care 2021, 1, 15. [CrossRef]

37. Muir, K.L.; Kallam, A.; Koepsell, S.A.; Gundabolu, K. Thrombotic thrombocytopenia after Ad26.COV2.S vaccination. N. Engl. J. Med. 2021, 384, 1964-1965. [CrossRef]

38. Pavord, B.; Scully, M.; Hunt, B.J.; Lester, W.; Bagot, C.; Craven, B.; Rampotas, A.; Ambler, G.; Makris, M. Clinical features of vaccine-induced immune thrombocytopenia and thrombosis. N. Engl. J. Med. 2021, 385, 1680-1689. [CrossRef]

39. Perry, R.J.; Tamborska, A.; Singh, B.; Craven, B.; Marigold, R.; Arthur-Farraj, P.; Yeo, J.M.; Zhang, L.; Hassan-Smith, G.; Jones, M.; et al. CVT After Immunisation Against COVID-19 (CAIAC) collaborators. Cerebral venous thrombosis after vaccination against COVID-19 in the UK: A multicentre cohort study. Lancet 2021, 398, 1147-1156. [CrossRef]

40. Pomara, C.; Sessa, F.; Ciaccio, M.; Dieli, F.; Esposito, M.; Garozzo, S.F.; Giarratano, A.; Prati, D.; Rappa, F.; Salerno, M.; et al Post-mortem findings in vaccine-induced thrombotic thombocytopenia. Haematologica 2021, 106, 2291-2293. [CrossRef]

41. Schultz, N.H.; Sørvoll, I.H.; Michelsen, A.E.; Munthe, L.A.; Lund-Johansen, F.; Ahlen, M.T.; Wiedmann, M.; Aamodt, A.H.; Skattør, T.H.; Tjønnfjord, G.E.; et al. Thrombosis and thrombocytopenia after ChAdOx1 nCoV-19 vaccination. N. Engl. J. Med. 2021, 384, 2124-2130. [CrossRef]

42. Schulz, J.B.; Berlit, P.; Diener, H.C.; Gerloff, C.; Greinacher, A.; Klein, C.; Petzold, G.; Poli, S.; Piccininni, M.; Kurth, T.; et al. COVID-19 Vaccine-associated cerebral venous thrombosis in Germany. Ann. Neurol. 2021, 90, 627-639. [CrossRef]

43. Smadja, D.M.; Yue, Q.Y.; Chocron, R.; Sanchez, O.; Lillo-Le Louet, A. Vaccination against COVID-19: Insight from arterial and venous thrombosis occurrence using data from VigiBase. Eur. Respir. J. 2021, 58, 2100956. [CrossRef] [PubMed]

44. Tølbøll Sørensen, A.L.; Rolland, M.; Hartmann, J.; Harboe, Z.B.; Roed, C.; Jensen, T.Ø.; Kolte, L.; El Fassi, D.; Hillingsø, J.; Radziwon-Balicka, A.; et al. Case of thrombocytopenia and multiple thromboses after vaccination with ChAdOx1 nCoV-19 against SARS-CoV-2. Blood Adv. 2021, 5, 2569-2574. [CrossRef] [PubMed]

45. Syed, K.; Chaudhary, H.; Donato, A. Central venous sinus thrombosis with subarachnoid hemorrhage following an mRNA COVID-19 vaccination: Are these reports merely co-incidental? Am. J. Case Rep. 2021, 22, e933397. [CrossRef]

46. Suresh, P.; Petchey, W. ChAdOx1 nCOV-19 vaccine-induced immune thrombotic thrombocytopenia and cerebral venous sinus thrombosis (CVST). BMJ Case Rep. 2021, 14, e243931. [CrossRef]

47. Vayne, C.; Nguyen, T.H.; Rollin, J.; Charuel, N.; Poupon, A.; Pouplard, C.; Normann, N.; Gruel, Y.; Greinacher, A. Characterization of new monoclonal PF4-specific antibodies as useful tools for studies on typical and autoimmune heparin-induced thrombocytopenia. Thromb. Haemost. 2021, 121, 322-331. [CrossRef] [PubMed]

48. Wiedmann, M.; Skattør, T.; Stray-Pedersen, A.; Romundstad, L.; Antal, E.A.; Marthinsen, P.B.; Sørvoll, I.H.; Leiknes Ernstsen, S.; Lund, C.G.; Holme, P.A.; et al. Vaccine induced immune thrombotic thrombocytopenia causing a severe form of cerebral venous thrombosis with high fatality rate: A case series. Front. Neurol. 2021, 12, 721146. [CrossRef]

49. Wolf, M.E.; Luz, B.; Niehaus, L.; Bhogal, P.; Bäzner, H.; Henkes, H. Thrombocytopenia and Intracranial venous sinus thrombosis after "COVID-19 vaccine AstraZeneca" exposure. J. Clin. Med. 2021, 10, 1599. [CrossRef] [PubMed] 
50. Yahyavi-Firouz-Abadi, N.; Naik, R.P. Cerebral venous sinus thrombosis associated with vaccine-induced thrombotic thrombocytopenia. Neuroradiol. J. 2021; in press. [CrossRef] [PubMed]

51. Zakaria, Z.; Sapiai, N.A.; Ghani, A.R.I. Cerebral venous sinus thrombosis 2 weeks after the first dose of mRNA SARS-CoV-2 vaccine. Acta Neurochir. 2021, 163, 2359-2362. [CrossRef]

52. Rizk, J.G.; Gupta, A.; Sardar, P.; Henry, B.M.; Lewin, J.C.; Lippi, G.; Lavie, C.J. Clinical Characteristics and pharmacological management of COVID-19 vaccine-induced immune thrombotic thrombocytopenia with cerebral venous sinus thrombosis: A review. JAMA Cardiol. 2021, 6, 1451-1460. [CrossRef] [PubMed]

53. Sharifian-Dorche, M.; Bahmanyar, M.; Sharifian-Dorche, A.; Mohammadi, P.; Nomovi, M.; Mowla, A. Vaccine-induced immune thrombotic thrombocytopenia and cerebral venous sinus thrombosis post COVID-19 vaccination; a systematic review. J. Neurol. Sci. 2021, 428, 117607. [CrossRef] [PubMed]

54. Lee, E.J.; Lee, A.I. Cerebral venous sinus thrombosis after vaccination: The UK experience. Lancet 2021, 398, 1107-1109. [CrossRef]

55. Ciccone, A. SARS-CoV-2 vaccine-induced cerebral venous thrombosis. Eur. J. Intern. Med. 2021, 89, 19-21. [CrossRef]

56. Otite, F.O.; Patel, S.; Sharma, R.; Khandwala, P.; Desai, D.; Latorre, J.G.; Akano, E.O.; Anikpezie, N.; Izzy, S.; Malik, A.M.; et al. Trends in incidence and epidemiologic characteristics of cerebral venous thrombosis in the United States. Neurology 2020, 95, e2200-e2213. [CrossRef]

57. Ferro, J.M.; Bousser, M.G.; Canhão, P.; Coutinho, J.M.; Crassard, I.; Dentali, F.; di Minno, M.; Maino, A.; Martinelli, I.; Masuhr, F.; et al. European stroke organization guideline for the diagnosis and treatment of cerebral venous thrombosis-endorsed by the European academy of neurology. Eur. J. Neurol. 2017, 24, 1203-1213. [CrossRef] [PubMed]

58. Levi, M.; Ten Cate, U. Disseminated intravascular coagulation. N. Engl. J. Med. 1999, 341, 586-592. [CrossRef]

59. Wasay, M.; Dai, A.I.; Ansari, M.; Shaikh, Z.; Roach, E.S. Cerebral venous sinus thrombosis in children: A multicenter cohort from the United States. J. Child Neurol. 2008, 23, 26-31. [CrossRef]

60. Ropper, A.H.; Klein, J.P. Cerebral venous thrombosis. N. Engl. J. Med. 2021, 385, 59-64. [CrossRef]

61. European Medicines Agency. AstraZeneca's COVID-19 Vaccine: EMA Finds Possible Link to Very Rare Cases of Unusual Blood Clots with Low Blood Platelets. EMA Website. Available online: https://www.ema.europa.eu/en/news/astrazenecas-covid-19 -vaccine-ema-finds-possible-link-very-rare-cases-unusual-blood-clots-low-blood (accessed on 8 June 2021).

62. Pottegård, A.; Lund, L.C.; Karlstad, Ø.; Dahl, J.; Andersen, M.; Hallas, J.; Lidegaard, Ø.; Tapia, G.; Gulseth, H.L.; Ruiz, P.L.; et al. Arterial events, venous thromboembolism, thrombocytopenia, and bleeding after vaccination with Oxford-AstraZeneca ChAdOx1-S in Denmark and Norway: Population based cohort study. BMJ (Clin. Res. Ed.) 2021, 373, n1114. [CrossRef]

63. Chaumont, H.; Etienne, P.; Roze, E.; Couratier, C.; Roger, P.-M.; Lannuzel, A. Acute meningoencephalitis in a patient with COVID-19. Rev. Neurol. 2020, 176, 519-521. [CrossRef]

64. Piazza, G.; Campia, U.; Hurwitz, S.; Snyder, J.E.; Rizzo, S.M.; Pfeferman, M.B.; Morrison, R.B.; Leiva, O.; Fanikos, J.; Nauffal, V.; et al. Registry of arterial and venous thromboembolic complications in patients with COVID-19. J. Am. Coll. Cardiol. 2020, 76, 2060-2072. [CrossRef] [PubMed]

65. Amiral, J.; Vissac, A.M.; Seghatchian, J. COVID-19, induced activation of hemostasis, and immune reactions: Can an auto-immune reaction contribute to the delayed severe complications observed in some patients? Transfus. Apher. Sci. 2020, 59, 102804. [CrossRef] [PubMed]

66. Gresele, P.; Marietta, M.; Ageno, W.; Marcucci, R.; Contino, L.; Donadini, M.P.; Russo, L.; Tiscia, G.L.; Palareti, G.; Tripodi, A.; et al. Management of cerebral and splanchnic vein thrombosis associated with thrombocytopenia in subjects previously vaccinated with Vaxzevria (AstraZeneca): A position statement from the Italian Society for the Study of Haemostasis and Thrombosis (SISET). Blood Transfus. 2021, 19, 281-283. [PubMed]

67. Terpos, E.; Politou, M.; Ntanasis-Stathopoulos, I.; Karalis, V.; Merkouri, E.; Fotiou, D.; Gavriatopoulou, M.; Malandrakis, P.; Kastritis, E.; Trougakos, I.P.; et al. High prevalence of anti-PF4 antibodies following ChAdOx1 nCov-19 (AZD1222) vaccination even in the absence of thrombotic events. Vaccines 2021, 9, 712. [CrossRef] [PubMed]

68. Ferro, J.M.; Canhão, P.; Stam, J.J.; Bousser, M.G.; Barinagarrementeria, F.; ISCVT Investigators. Prognosis of cerebral vein and dural sinus thrombosis: Results of the International Study on Cerebral Vein and Dural Sinus Thrombosis (ISCVT). Stroke 2004, 35 , 664-670. [CrossRef]

69. Virchow, R.L.K. Thrombose und Embolie. Gefäßentzündung und Septische Infektion. Gesammelte Abhandlungen zur Wissenschaftlichen Medicin; Von Meidinger \& Sohn: Frankfurt, Germany, 1856; pp. 219-732.

70. Lowe, G.D. Virchow's triad revisited: Abnormal flow. Pathophysiol. Haemost. Thromb. 2003, 33, 455-457. [CrossRef]

71. Calcaterra, G.; Bassareo, P.P.; Barillà, F.; Romeo, F.; Mehta, J.L. Concerning the unexpected prothrombotic state following some coronavirus disease 2019 vaccines. J. Cardiovasc. Med. 2022, 23, 71-74. [CrossRef]

72. Andreozzi, G.M.; Signorelli, S.; Di Pino, L.; Garozzo, S.; Cacciaguerra, G.; Leone, A.; Martini, R. Varicose symptoms without varicose veins: The hypotonic phlebopathy, epidemiology and pathophysiology. The Acireale project. Minerva Cardioangiol. 2000, $48,277-285$.

73. Sánchez van Kammen, M.; Aguiar de Sousa, D.; Poli, S.; Cordonnier, C.; Heldner, M.R.; van de Munckhof, A.; Krzywicka, K.; van Haaps, T.; Ciccone, A.; Middeldorp, S.; et al. Cerebral venous sinus thrombosis with thrombocytopenia syndrome study group. characteristics and outcomes of patients with cerebral venous sinus thrombosis in SARS-CoV-2 vaccine-induced immune thrombotic thrombocytopenia. JAMA Neurol. 2021, 78, e213619. [CrossRef] 
74. Bai, C.; Ding, J.; Da, Z.; Sun, J.; Liu, C.; Pan, L.; Ya, J.; Wang, Z.; Guan, J.; Jin, K.; et al. Probable risk factors of internal jugular vein stenosis in Chinese patients. A real-world cohort study. Clin Neurol. Neurosurg. 2020, 191, 105678. [CrossRef] [PubMed]

75. Wang, L.; Harrison, J.; Dranow, E.; Aliyev, N.; Khor, L. Accuracy of ultrasound jugular venous pressure height in predicting central venous congestion. Ann. Intern. Med. 2021, in press. [CrossRef]

76. Tomar, B.; Anders, H.J.; Desai, J.; Mulay, S.R. Neutrophils and neutrophil extracellular traps drive necroinflammation in COVID-19. Cells 2020, 9, 1383. [CrossRef]

77. McNeil, M.M.; DeStefano, F. Vaccine-associated hypersensitivity. J. Allergy Clin. Immunol. 2018, 141, 463-472. [CrossRef] [PubMed]

78. Tanno, L.K.; Berard, F.; Beaudoin, E.; Didier, A.; Demoly, P.; on behalf of the Montpellier WHO Collaborating Center. SARSCoV-2 Vaccination and Anaphylaxis: Recommendations of the French Allergy Community and the Montpellier World Health Organization Collaborating Center. Vaccines 2021, 9, 560. [CrossRef] [PubMed]

79. Ieven, T.; Van Weyenbergh, T.; Vandebotermet, M.; Devolder, D.; Breynaert, C.; Schrijvers, R. Tolerability of polysorbate 80containing COVID-19 vaccines in confirmed polyethylene glycol-allergic patients. J. All. Clin. Immunol. Pract. 2021, 9, 4470-4472. [CrossRef]

80. Rhim, J.W.; Kang, J.H.; Lee, K.Y. Etiological and pathophysiological enigmas of severe coronavirus disease 2019, multisystem inflammatory syndrome in children, and Kawasaki disease. Clin. Exp. Pediatr. 2022; in press. [CrossRef]

81. Allegra, A.; Di Gioacchino, M.; Tonacci, A.; Musolino, C.; Gangemi, S. Immunopathology of SARS-CoV-2 infection: Immune cells and mediators, prognostic factors, and immune-therapeutic implications. Int. J. Mol. Sci. 2020, 21, 4782. [CrossRef]

82. Gong, T.; Liu, L.; Jiang, W.; Zhou, R. DAMP-sensing receptors in sterile inflammation and inflammatory diseases. Nat. Rev. Immunol. 2020, 20, 95-112. [CrossRef]

83. Zindel, J.; Kubes, P. DAMPs, PAMPs, and LAMPs in immunity and sterile inflammation. Annu. Rev. Pathol. 2020, 15, 493-518. [CrossRef] 